University of Nebraska - Lincoln

DigitalCommons@University of Nebraska - Lincoln

U.S. Environmental Protection Agency Papers

U.S. Environmental Protection Agency

2012

\title{
Laboratory evaluation of large-scale decontamination approaches
}

M. W. Calfee

U.S. Environmental Protection Agency, calfee.worth@epa.gov

S. P. Ryan

U.S. Environmental Protection Agency

J. P. Wood

U.S. Environmental Protection Agency

L. Mickelsen

U.S. Environmental Protection Agency

C. Kempter

U.S. Environmental Protection Agency

See next page for additional authors

Follow this and additional works at: https://digitalcommons.unl.edu/usepapapers

Calfee, M. W.; Ryan, S. P.; Wood, J. P.; Mickelsen, L.; Kempter, C.; Miller, L.; Colby, M.; Touati, A.; Clayton, M.; Griffin-Gatchalian, N.; McDonald, S.; and Delafield, R., "Laboratory evaluation of large-scale decontamination approaches" (2012). U.S. Environmental Protection Agency Papers. 117. https://digitalcommons.unl.edu/usepapapers/117

This Article is brought to you for free and open access by the U.S. Environmental Protection Agency at DigitalCommons@University of Nebraska - Lincoln. It has been accepted for inclusion in U.S. Environmental Protection Agency Papers by an authorized administrator of DigitalCommons@University of Nebraska - Lincoln. 


\section{Authors}

M. W. Calfee, S. P. Ryan, J. P. Wood, L. Mickelsen, C. Kempter, L. Miller, M. Colby, A. Touati, M. Clayton, N. Griffin-Gatchalian, S. McDonald, and R. Delafield 


\title{
ORIGINAL ARTICLE
}

\section{Laboratory evaluation of large-scale decontamination approaches}

\author{
M.W. Calfee ${ }^{1}$, S.P. Ryan ${ }^{1}$, J.P. Wood ${ }^{1}$, L. Mickelsen ${ }^{2}$, C. Kempter ${ }^{3}$, L. Miller ${ }^{4}$, M. Colby ${ }^{5}$, A. Touati ${ }^{6}$, \\ M. Clayton ${ }^{6}$, N. Griffin-Gatchalian ${ }^{6}$, S. McDonald ${ }^{6}$ and R. Delafield ${ }^{6}$ \\ 1 US EPA, Office of Research and Development, National Homeland Security Research Center, Research Triangle Park, NC, USA \\ 2 US EPA, Office of Emergency Management, National Decontamination Team, Research Triangle Park, NC, USA \\ 3 US EPA, Office of Chemical Safety and Pollution Prevention, Arlington, VA, USA \\ 4 US Department of Agriculture, Animal and Plant Health Inspection Service, Riverdale, MD, USA \\ 5 US Department of Homeland Security, Science and Technology Directorate, Washington, DC, USA \\ 6 Arcadis Geraghty \& Miller, Inc., Durham, NC, USA
}

\section{Keywords}

Anthrax, Bacillus anthracis, biological agent, decontamination, facility remediation, foreign animal disease, spore, sporicide, wide-area incident.

\section{Correspondence \\ Michael W. Calfee, US EPA, MD E343-06; 109 TW Alexander Dr., Research Triangle Park, NC 27711, USA. \\ E-mail: calfee.worth@epa.gov}

2011/2201: received 28 December 2011, revised 7 February 2012 and accepted 8 February 2012

doi:10.1111/j.1365-2672.2012.05259.x

\begin{abstract}
Aims: To evaluate the effectiveness of two spray-based decontamination methods for surface contamination reduction and to determine the potential for contamination spread by these methods.

Methods and Results: Material coupons (treated plywood and concrete) were contaminated with c. $1 \times 10^{7}$ spores of Bacillus atrophaeus by aerosol deposition. Decontaminants (pH-adjusted bleach or Spor-Klenz ${ }^{\circledR}$ RTU) were applied to coupons by either backpack sprayer or gas-powered sprayer. Contact time, reapplication frequency and rinse method were also varied. In addition to surface removal efficacy, partitioning of contamination between the rinsate and aerosol fractions was determined. Results indicated that $\mathrm{pH}$-adjusted bleach was effective ( $\geq 6$ logs reduction) when two applications and a 30 min contact time were administered, regardless of the decontaminant application method or material. Spor-Klenz ${ }^{\circledR}$ RTU was effective on wood, but achieved $\leq 3 \operatorname{logs}$ reduction on concrete. A shortened application procedure with $\mathrm{pH}$-adjusted bleach resulted in lower efficacy on wood, and a greater apparent potential for contamination spread.

Conclusions: Consideration of material surface type is important when selecting a decontaminant. Also, achieving conditions that effectively inactivate surface biological contamination are critical to preventing the spread of contamination.

Significance and Impact of the Study: Results presented here are intended to help development of remediation plans following a biological contamination incident.
\end{abstract}

\section{Introduction}

Biological decontamination is the removal of microorganisms from inanimate objects so they can be safely handled, used or discarded (Rutala 2007). Extensive decontamination of facilities and outdoor areas will likely be required following a large-scale contamination event such as a foreign animal disease (FAD) outbreak or widearea bioterror incident (Franco and Bouri 2010; Raber et al. 2011). Surface decontamination procedures are among those methods likely to be deployed to reduce the risk of infection and disease propagation following such incidents (Krauter et al. 2011).

A holistic understanding of decontamination approaches is vital for overall remediation success. For example, surface decontamination, waste generation, waste disposal, contamination spread, time and cost are all interconnected variables that must be considered and balanced collectively. Test tube-based studies are useful for predicting the efficacy of decontaminants for various 
contaminated surfaces; however, they are not meant to capture the full perspective of a large-scale decontamination. Indentifying potential routes of cross-contamination caused by decontamination procedures, optimizing the deployment of various decontamination methodologies and understanding material interaction with chemical decontaminants are all important parameters that should be evaluated with a more operational scale of experimentation.

One mission of the US Environmental Protection Agency's (EPA) National Homeland Security Research Center (NHSRC) is to provide scientifically proven and practical remediation options following biological contamination incidents. Laboratory testing of decontamination approaches, using stringent quality assurance measures, highly controlled test conditions and adequate replication, increase the likelihood that remediation action plans will be successful in the field.

This study evaluated the effectiveness of biological agent removal and inactivation for two liquid decontaminants (pH-adjusted bleach and Spor-Klenz ${ }^{\circledR}$ Ready to Use) and two surface decontaminant application methods (a backpack sprayer- and a gas-powered sprayer-based method). Two materials (concrete and treated plywood) commonly found in outdoor or animal facility environments were experimentally contaminated with the surrogate biological agent Bacillus atrophaeus (spores). Surface decontamination efficacy, as well as the potential for contamination spread during decontamination by liquid runoff or fugitive aerosol was determined.

\section{Materials and methods}

\section{Bacterial spore preparation}

Spores of Bacillus atrophaeus (ATCC 9372; formerly Bacillus subtilis var. niger, subsequently Bacillus globigii) (Nakamura 1989) were used as surrogates for an FAD or bioterror agent. Spore preparations were obtained from the US Army Dugway Proving Ground (Utah) and have been described previously (Brown et al. 2007a). Briefly, after $80-90 \%$ sporulation, the suspension was centrifuged to generate a preparation of about $20 \%$ solids. A preparation resulting in a powdered matrix containing $c$. $1 \times 10^{11}$ viable spores per gram was prepared by dry blending and jet milling the dried spores with fumed silica particles (Deguss, Frankfurt am Main, Germany). The powdered preparation was loaded into metered dose inhalers (MDIs) by the US Army Edgewood Chemical Biological Center (ECBC) according to a proprietary protocol. According to the manufacturer, the MDIs provide a consistent dose of $c .1 \times 10^{8}$ aerosolized spores per actuation.

\section{Preparation and inoculation of material coupons}

Pressure-treated plywood (alkaline copper quaternary type D, 0.75 in thick, Georgia-Pacific, Atlanta GA) was cut into $35.56 \mathrm{~cm}$ by $35.56 \mathrm{~cm}$ (14 in by 14 in) coupons using a table saw. The pressure-treated plywood (hereafter referred to as wood) coupons were sterilized prior to the decontamination with a $240 \mathrm{~min}$ exposure to $\geq 250$ parts per million by volume (ppmv) $\mathrm{H}_{2} \mathrm{O}_{2}$ generated by a STERIS VHP ${ }^{\circledR}$ ARD generator (STERIS Corp., Mentor, $\mathrm{OH}$, USA). Concrete coupons were fabricated by mixing Quikrete $^{\circledR}$ Sand/Topping Mix (Atlanta, GA, USA) according to the manufacturer's instructions and pouring into $35.56 \times 35.56 \times 3.81 \mathrm{~cm}(14 \times 14 \times 1.5$ in $)$ moulds. Surfaces were smoothed with a hand trowel, then covered with plastic sheeting and allowed to cure for $\geq 5$ days. Prior to use in testing, loose grit was removed from the concrete coupons by spraying them with water using a pressure washer. Concrete coupons were sterilized following the pressure wash by subjecting them to a 1 -h gravity autoclave cycle at $121^{\circ} \mathrm{C}$ and $103 \mathrm{kPa}$. Prior to testing, the sterility of all coupons was confirmed by swab sampling one coupon from each sterilization batch, streaking the swab onto tryptic soy agar plates (TSA; Difco, Franklin Lakes, NJ, USA) and incubating plates at $35-37^{\circ} \mathrm{C}$ for 18-24 h.

Coupon surfaces were inoculated with $c .1 \times 10^{8}$ spores by a method described previously (Lee et al. 2011), but modified for inoculation of $35.56 \times 35.56 \mathrm{~cm}(14 \times 14 \mathrm{in})$ coupons. To verify that inoculums were consistent within an experiment, three stainless steel control coupons were also inoculated during each inoculation event, one each at the beginning, middle and end of the material coupon inoculation sequence. These inoculation control coupons were inoculated, sampled and analysed with the same methods used for test coupons. Sampling stainless steel surfaces is known to provide higher, more repeatable recoveries than porous materials such as wood or concrete (Brown et al. 2007a,b; Probst et al. 2011). The target recovery was $1 \times 10^{7}$ spores for stainless steel, and $1 \times 10^{6}$ spores for wood and concrete.

\section{Decontamination chamber}

Decontamination tests were conducted inside a custombuilt $1.82 \mathrm{~m}^{3}$ chamber $(1.22 \times 1.22 \times 1.22 \mathrm{~m})$ constructed of stainless steel and clear acrylic plastic. The chamber accommodated three vertically oriented coupons at one time, positioned adjacently along the chamber's rear wall. The front wall of the chamber was constructed of clear acrylic plastic, mounted onto steel support beams and hinged so that the entire interior of the chamber could be accessed while remaining outside the chamber. In 
addition, three swivel ports were located across the front face of the door, which allowed insertion of spray nozzles into the chamber so that decontamination methods could be executed with the door closed. By conducting tests with the chamber door in the closed position, sample integrity was increased by reducing cross-contamination; exposure of laboratory workers to decontaminant vapours, aerosols and liquids was also decreased. When the chamber was in use and the door was in the closed position, a slight negative pressure was maintained inside the chamber by its connection to the facility exhaust ventilation system. Air entered the chamber through a HEPA filter $(61 \times 61 \times 15 \mathrm{~cm}$; BIOMAX HEPA; Koch Filter Corporation, Louisville, KY, USA) to reduce unintended contamination during testing. The floor of the chamber was constructed of stainless steel and is pyramidal in shape with a $7.6 \mathrm{~cm}$ (3 in) diameter drain in the center. The drain can be closed or opened to either collect or release the rinsate from the coupons during the decontamination procedure. The bottom of the chamber has a 227 l (50 gal) collection capacity. The chamber was designed to be easily decontaminated between tests.

\section{Test conditions and decontamination procedures}

All tests were conducted under approximate room temperature conditions $\left(22 \pm 3^{\circ} \mathrm{C}, 40 \pm 15 \%\right.$ r.h. $)$. Each test consisted of six replicate inoculated coupons subjected to the decontamination procedure, six replicate inoculated coupons not subjected to the decontamination procedure (positive controls) and one negative control coupon that was neither inoculated nor subjected to the decontamination procedure.

Initially, four tests were conducted, each with two material types (concrete and wood). The details of each test are outlined in Table 1 and are as follows: two decontamination procedures were evaluated with two different liquid decontaminants over the four tests. The decontaminants evaluated were as follows: 1) $\mathrm{pH}$-adjusted bleach (hypochlorous acid based) and 2) Spor-Klenz ${ }^{\circledR}$ Ready to Use (RTU) (STERIS Corp.) (hydrogen peroxide and peracetic acid based). The $\mathrm{pH}$-adjusted bleach was prepared as described previously (Calfee et al. 2011) that is, one part Clorox Bleach (Clorox Corp., Oakland, CA, USA) was diluted with eight parts deionized water and one part 5\% (v/v) acetic acid (Fisher Scientific, Pittsburgh, PA, USA; Part no. 13025). The $\mathrm{pH}$ was adjusted to $6 \cdot 5-7 \cdot 0$ with $5 \%$ acetic acid, and the free available chlorine content was adjusted to 6000$6800 \mathrm{ppmv}$ with deionized water after preparation. The $\mathrm{pH}$-adjusted bleach was prepared fresh for each day of testing and used within $3 \mathrm{~h}$. The Spor-Klenz ${ }^{\circledR}$ RTU was used undiluted from a new, unopened bottle each day of testing. The active components in Spor-Klenz ${ }^{\circledR}$ RTU are $1 \%(\mathrm{v} / \mathrm{v})$ hydrogen peroxide and $0 \cdot 08 \%(\mathrm{v} / \mathrm{v})$ peroxyacetic acid (EPA Registration no. 1043-119).

The first decontamination procedure (Procedure no. 1) involved spraying the decontaminant on the coupon surface with a pressurized $\left(241 \pm 34 \mathrm{kPa}, 11 \mathrm{~min}^{-1}\right)$ backpack sprayer (SRS-600; SHURflo, Cypress, CA, USA) for $30 \mathrm{~s}$ (per three coupons) with two applications (time $=0$ and time $=15 \mathrm{~min}$ ). After a $30 \mathrm{~min}$ total contact time,

Table 1 Summary of test parameters and decontamination procedures

\begin{tabular}{|c|c|c|c|c|c|c|c|c|}
\hline Test & Material* & Decontaminant & $\begin{array}{l}\text { Decon application } \\
\text { method }\end{array}$ & $\begin{array}{l}\text { Duration of } \\
\text { decon } \\
\text { application (s) } \dagger\end{array}$ & $\begin{array}{l}\text { Timing of decon } \\
\text { applications (min) }\end{array}$ & $\begin{array}{l}\text { Rinse } \\
\text { application } \\
\text { method (s) }\end{array}$ & $\begin{array}{l}\text { Duration of } \\
\text { rinse }(s) \dagger\end{array}$ & $\begin{array}{l}\text { Timing of } \\
\text { rinse (min) }\end{array}$ \\
\hline 1 & $\begin{array}{l}\text { Concrete } \\
\text { Wood }\end{array}$ & pH-adjusted bleach & Backpack sprayer & 30 & 0,15 & Garden hose & 10 & 30 \\
\hline 2 & $\begin{array}{l}\text { Concrete } \\
\text { Wood }\end{array}$ & pH-adjusted bleach & $\begin{array}{l}\text { Gas-powered } \\
\text { sprayer }\end{array}$ & 15 & 0,15 & $\begin{array}{l}\text { Gas-powered } \\
\text { sprayer§ }\end{array}$ & 10 & 30 \\
\hline 3 & $\begin{array}{l}\text { Concrete } \\
\text { Wood }\end{array}$ & Spor-Klenz ${ }^{\circledR}$ RTU & Backpack sprayer & 30 & 0,15 & Garden hose & 10 & 30 \\
\hline 4 & $\begin{array}{l}\text { Concrete } \\
\text { Wood }\end{array}$ & Spor-Klenz ${ }^{\circledR}$ RTU & $\begin{array}{l}\text { Gas-powered } \\
\text { sprayer** }\end{array}$ & 15 & 0,15 & $\begin{array}{c}\text { Gas-powered } \\
\text { sprayer**}, \S^{*},\end{array}$ & 10 & 30 \\
\hline 5 & $\begin{array}{l}\text { Concrete } \\
\text { Wood }\end{array}$ & pH-adjusted bleach & Backpack sprayer & 10 & 0 & Garden hose & 10 & 15 \\
\hline
\end{tabular}

*Six replicate coupons per material.

$\nmid$ Per set of three replicate coupons.

\$UDOR Chemical Sprayer (Model PP-UAG1003HU-K).

§Troy-Bilt 2550 psi Pressure Washer (Model 020337).

-Gas-powered sprayer malfunction, only three of six wood replicates decontaminated, only one of two applications was administered to these three replicate coupons, rinse administered at $34 \mathrm{~min}$.

**John Deere 3300 psi Pressure Washer (Model 020382). 
the coupons were rinsed for $10 \mathrm{~s}$ (per three coupons) with a garden hose $(22.86 \mathrm{~m}, 1.59 \mathrm{~cm}$ diameter, $414 \mathrm{kPa}$, $12.91 \mathrm{~min}^{-1}$ ) delivering deionized water (Dracor Model 34RC3; Durham, NC, USA) from a 2271 (60 gal) tank. The second decontamination procedure (Procedure no. 2) required spraying the decontaminant onto the coupon surface with a gas-powered pressurized sprayer (John Deere Model $020382,2.28 \times 10^{4} \mathrm{kPa}, 12 \cdot 11 \mathrm{~min}^{-1}$, Moline, Illinois; or a UDOR Model PP-UAG1003HU-K, $2.07 \times 10^{3} \mathrm{kPa}, 39.71 \mathrm{~min}^{-1}$, Lino Lakes, MN) for $15 \mathrm{~s}$ (per three coupons) at time $=0$ and time $=15 \mathrm{~min}$. After a $30 \mathrm{~min}$ total contact time, the coupons were rinsed for $10 \mathrm{~s}$ (per three coupons) using a gas-powered pressurized sprayer (John Deere Model 020382; or Troy-Bilt ${ }^{\circledR}$ Model 020337, $1.76 \times 10^{4} \mathrm{kPa}, 8.71 \mathrm{~min}^{-1}$; Valley City, $\mathrm{OH}$, USA) dispensing deionized water.

After obtaining results from the first four tests, a fifth test was designed and conducted. This test utilized a single application, whereby coupons were sprayed with $\mathrm{pH}$-adjusted bleach for $10 \mathrm{~s}$ (per three coupons) at time $=0$ only, using a backpack sprayer. Following a 15 min total contact time, coupons were rinsed with deionized water for $10 \mathrm{~s}$ (per three coupons) using a garden hose. Following all decontamination procedures, coupons were stored overnight in a metal cabinet under slight positive pressure at room temperature to promote drying.

\section{Surface samples}

Sampling of coupon surfaces was conducted the day following decontamination. Collection of spores from coupon surfaces was accomplished by gauze wipe sampling according to the methods described by the US Centers for Disease Control (US Centers for Disease Control and Prevention, 2010), which was modified by substituting phosphate buffered saline with Tween 20 (PBST; Sigma Aldrich, St Louis, MO, USA) for neutralizing buffer (Hardy Diagnostics, Santa Maria, CA, USA) as the wetting agent. PBST has demonstrated increased sampling efficiency over wetting agents without surfactant (Da Silva et al. 2011).

Following surface sample collection, spores were extracted from the wipes by aseptically placing the wipe into a $50 \mathrm{ml}$ conical tube containing $20 \mathrm{ml}$ PBST, then agitating the tubes using a vortex mixer (set to maximum rotation) for $2 \mathrm{~min}$ in $10 \mathrm{~s}$ intervals. Undiluted extracts and 10-fold serially diluted extracts (in PBST) were then plated onto TSA (Difco). Plates were incubated at 35$37^{\circ} \mathrm{C}$ for $18-24 \mathrm{~h}$ and colony forming units (CFU) were enumerated. When fewer than $30 \mathrm{CFU}$ were detected on plates, the remainder of the extract was analysed by filtration through $0 \cdot 2 \mu \mathrm{m}$ pore-size filters (Nalgene, Rochester,
NY, USA), and placing filters onto TSA plates followed by incubation at $35-37^{\circ} \mathrm{C}$ for $18-24 \mathrm{~h}$.

Recovery was determined for each material type by comparing the number of recovered spores from positive control (inoculated, not decontaminated) test material coupons to that of inoculated stainless steel coupons. For each of the two material types, the average recovery value was calculated for each test using the six positive control samples.

The surface reduction (decontamination) efficacy of each procedure was quantified by determining the difference in recovered viable spores between positive control coupons and test coupons for each coupon material and expressed as 'Log Reduction'. Six replicates of each were used to determine the log reduction (LR) values for each procedure on each material according to Eqn (1):

$$
\text { Efficacy }=\overline{\left(\log _{10} \text { CFUc }\right)}-\overline{\left(\log _{10} \text { CFUt }\right)}
$$

where CFUc is the abundance of colonies recovered from positive control samples, and CFUt is the abundance of colonies recovered from test samples. The mean $\log _{10}$ values from six replicate test samples were subtracted from the mean $\log _{10}$ values from six positive control samples.

\section{Rinsate samples}

Application overspray and runoff from the coupons during the decontamination and rinse procedures was collected and pooled for each set of six replicate coupons. During the decontamination procedures, all liquid was allowed to flow through the spray chamber drain into a 201 polypropylene carboy, where residual decontaminant was neutralized immediately. Neutralization was achieved by the addition of a molar-equivalent amount of sodium thiosulfate to carboys prior to collection of rinsate samples so that inactivation of bioagent postcollection was inhibited and accurate estimates of viable agent being removed from the coupon surfaces during decontamination could be determined. After collection of rinsate for each set of replicates, the carboy was capped, shaken vigorously to homogenize the contents, and three replicate $100 \mathrm{ml}$ aliquots were removed using a serological pipette. The abundance of viable agent collected in rinsate samples was determined by plating undiluted and a series of 10 -fold diluted samples of each aliquot onto TSA plates and incubating at $35-37^{\circ} \mathrm{C}$ for $18-24 \mathrm{~h}$. To lower the limit of detection, spores from $1 \mathrm{ml}$ and $99 \mathrm{ml}$ aliquots were collected by filtration onto $0 \cdot 2 \mu \mathrm{m}$ pore-size filters (Nalgene). CFU were enumerated on filters following placement onto TSA plates and incubation at $35-37^{\circ} \mathrm{C}$ for 18-24 h. Data are reported as the mean total recovered CFU \pm 1 standard deviation. 


\section{Bioaerosol samples}

To assess the potential for contamination spread via the formation of spore-containing aerosols during the decontamination process, aerosol samples were collected by actively sampling $151 \mathrm{~min}^{-1}$ of air from the chamber with a ViaCell ${ }^{\circledR}$ (Zephon, Ocala, FL, USA) bioaerosol collection cassette. For each set of replicate test or control coupons, one composite aerosol sample was collected during the entirety of decontaminant spraying and rinsing. The aerosol sample collection intake was inserted into the decontamination chamber through the chamber ceiling, which was located $c .60 \mathrm{~cm}$ in front of the coupons. The abundance of viable spores collected by aerosol sampling was determined by extracting the filters according to the manufacturer's instructions and subsequently plating undiluted extract and a series of 10-fold diluted extracts of each sample onto TSA plates and incubating at $35-37^{\circ} \mathrm{C}$ for $18-24 \mathrm{~h}$. Data are reported as the abundance of recovered CFU per litre of air sampled.

\section{Results}

\section{Inoculation and recovery from material surfaces}

Recoveries from all stainless steel inoculation control coupons were above $1 \times 10^{7}$ (mean recovery of $2.63 \times 10^{7}$, $n=15$ ), indicating that all coupons (test and control coupons) were inoculated with the target dose (Fig. 1). Recoveries from concrete and wood positive control cou-

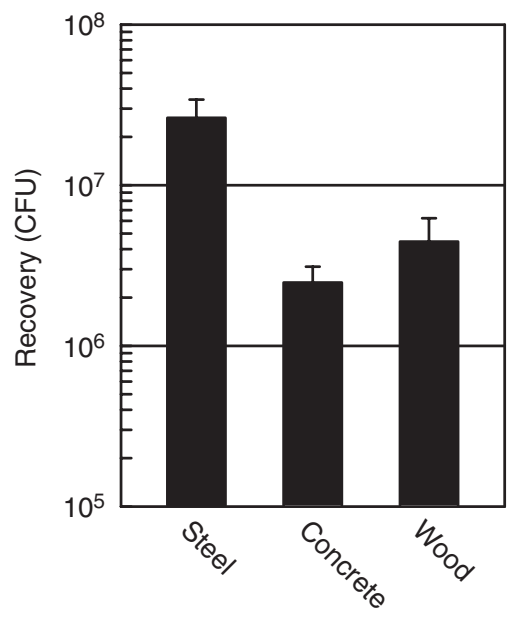

Figure 1 Recovery from stainless steel inoculation control coupons, as well as concrete and wood positive control coupons by wipe sampling. Data are reported as mean recovered CFU \pm 1 standard deviation, across all five tests. Each test consisted of three stainless steel, six concrete and six wood replicates, therefore $n=15,30$ and 30, for stainless steel, concrete and wood, respectively. pons were $1.46 \times 10^{6}-3.05 \times 10^{6}$ and $1.88 \times 10^{6}-$ $6 \cdot 71 \times 10^{6}$, respectively.

\section{Surface decontamination efficacy}

Surface decontamination efficacy was high ( $\geq 6$ LR) for both concrete and wood during Tests 1 and 2, where $\mathrm{pH}$ adjusted bleach was applied to surfaces using Procedures 1 (backpack sprayer) and 2 (gas-powered sprayer), respectively (Fig. 2). No viable spores were recovered from concrete following decontamination during Test 1 , and none were recovered from wood following decontamination during Test 2. In Tests 3 and 4 with Spor-Klenz ${ }^{\circledR}$ RTU, both procedures demonstrated similar results. During these tests, surface reduction efficacy was much higher for wood ( $\geq 6$ LR) than for concrete (LRs of $<2$ and $<3$ for Tests 3 and 4 , respectively) ( $t$-test, $P \leq 0 \cdot 001$ ). No viable spores were recovered from wood following decontamination with Spor-Klenz ${ }^{\circledR}$ RTU (Tests 3 and 4). During Test 5, an abbreviated $\mathrm{pH}$-adjusted bleach application was used. Results from this test suggest that the shortened procedure was able to achieve $\geq 6$ LR on concrete, but only four LR on wood. Viable spores were recovered from both wood and concrete following this procedure.

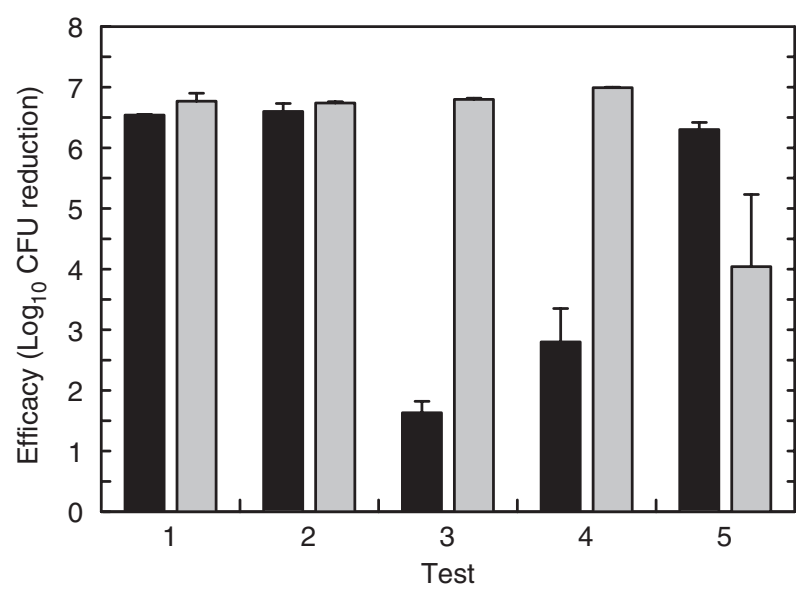

Figure 2 Surface decontamination efficacy for concrete (black bars) and wood (grey bars). Reduction in surface contamination is determined by the difference in the mean log recovery of positive control samples and the mean log recovery from decontaminated samples. Data are reported as the mean $\log _{10}$ reduction in recovered CFU, \pm 1 standard deviation from six replicates. Conditions for each test are outlined in Table 1, and are as follows: Test $1-\mathrm{pH}$-adjusted bleach, backpack sprayer, two applications; Test 2 - pH-adjusted bleach, gaspowered sprayer, two applications; Test 3 - Spor-Klenz ${ }^{\circledR}$ RTU, backpack sprayer, two applications; Test $4-$ Spor-Klenz ${ }^{\circledR}$ RTU, gas-powered sprayer, two applications; Test $5-\mathrm{pH}$-adjusted bleach, backpack sprayer, one application. 


\section{Recovery from decontamination rinsates and aerosols}

Viable cells were detected in rinsates only during Test 2 (concrete only) and Test 5 (both concrete and wood) (Fig. 3). Mean rinsate recovery during Test 5 was significantly greater than that of all other tests ( $t$-test, $P \leq 0.001)$. Viable cells were also detected in aerosol samples collected from all five tests (Fig. 4). Similar to the rinsate results, the highest recoveries were collected in Test 5, during the abbreviated $\mathrm{pH}$-adjusted bleach procedure.

\section{Discussion}

Decontamination strategies following a large-scale biological incident (e.g. wide-area bioterror attack or FAD outbreak) for outdoor areas, large facilities (e.g. warehouses or agriculture industry structures) or mass transit depots (e.g. subway platforms and tunnels) will likely require extensive amounts of surface treatment with biocidal chemicals (Krauter et al. 2011). Efficient application of decontaminants over vast amounts of surface area may require the use of backpack sprayers and gas-powered pressurized sprayers. Current strategies require application of the decontaminant to the surface, keeping the surface wetted for a predetermined amount of time with reappli-

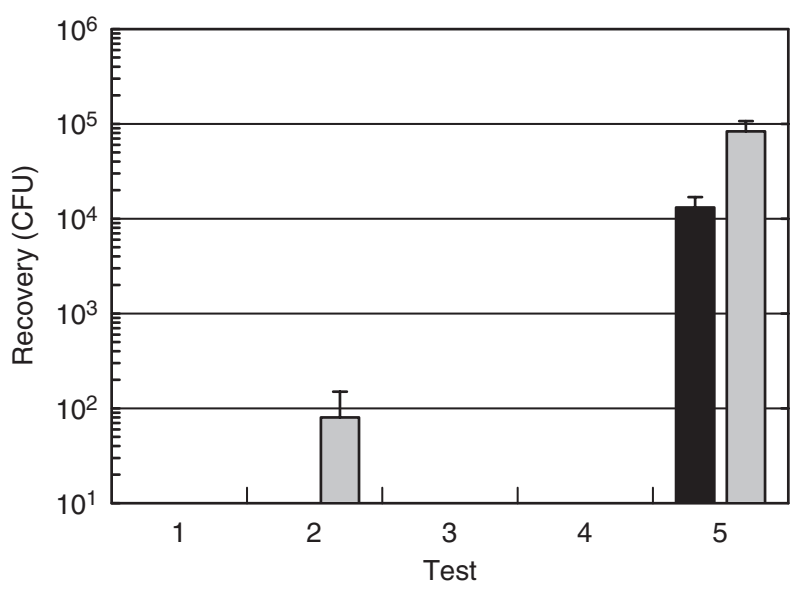

Figure 3 Recovery of viable biological agent in rinsate samples. Triplicate rinsate samples were collected during concrete (black bars) and wood (grey bars) decontamination procedures and analysed for surviving biological agent. Data are reported as the mean $( \pm 1$ standard deviation) recovered CFU per total volume of rinsate collected for each six replicates of one material in each test. Test conditions are as follows: Test 1 - pH-adjusted bleach, backpack sprayer, two applications; Test 2 - pH-adjusted bleach, gas-powered sprayer, two applications; Test 3 - Spor-Klenz ${ }^{\circledR}$ RTU, backpack sprayer, two applications; Test 4 - Spor-Klenz ${ }^{\circledR}$ RTU, gas-powered sprayer, two applications; Test 5 - pH-adjusted bleach, backpack sprayer, one application. cations as necessary, then rinsing the surface to remove residual decontaminant thereby reducing the potential for corrosion (if metal-based materials are present). The current study adopted this approach, yet varied the decontaminant delivery method, decontaminant type and material type over four tests. For these tests, spray volumes and the timing of reapplications were selected based upon the ability to maintain a wetted surface for the duration of a $30 \mathrm{~min}$ contact time. A fifth test was then conducted whereby the application procedure was significantly shortened, in attempts to reduce the time required for remediation, but potentially without negatively affecting the efficacy of the treatment. All tests were conducted with spores of Bacillus atrophaeus as a surrogate infectious agent (e.g. bioterror agent or FAD). This organism is used frequently as a surrogate for Bacillus anthracis (causative agent of Anthrax). It, however, may be more resistant or less resistant to chemical inactivation than viral or prion agents, respectively (McDonnell and Russell 1999; Grand et al. 2010).

Surface sampling of positive control coupons (not decontaminated) and test coupons (decontaminated) was conducted to determine the reduction in surface contamination following the decontamination procedures. Typically, procedures resulting in $\geq 6$ LR when challenged with a surface load of $1 \times 10^{6}$ or greater are considered

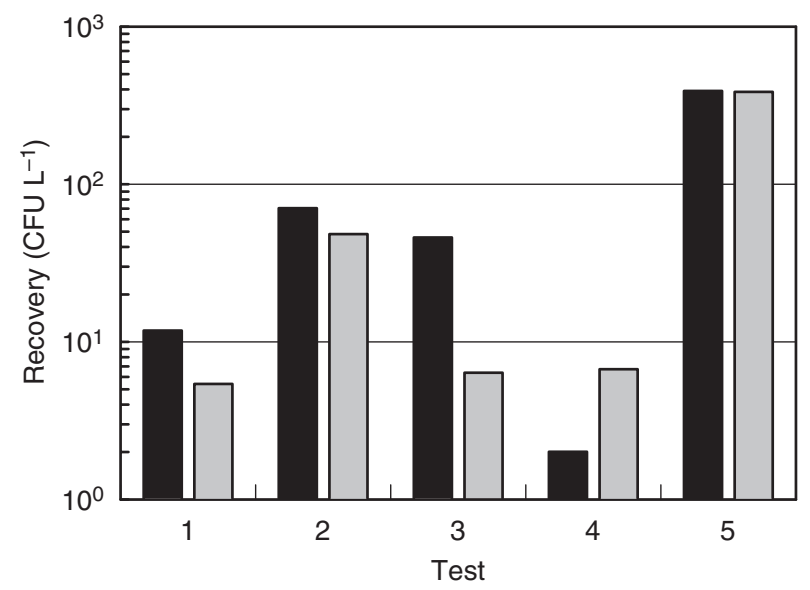

Figure 4 Recovery of viable biological agent in aerosol samples. One composite aerosol sample was collected during each concrete (black bars) and wood (grey bars) decontamination test and analysed for biological agent. Data are reported as recovered CFU per litre of air sampled for each set of six replicates of one material in each test. Test conditions are as follows: Test $1-\mathrm{pH}$-adjusted bleach, backpack sprayer, two applications; Test 2 - pH-adjusted bleach, gas-powered sprayer, two applications; Test 3 - Spor-Klenz ${ }^{\circledR}$ RTU, backpack sprayer, two applications; Test 4 - Spor-Klenz ${ }^{\circledR}$ RTU, gas-powered sprayer, two applications; Test 5 - pH-adjusted bleach, backpack sprayer, one application. 
efficacious (US Environmental Protection Agency, 2007). Using this benchmark, $\mathrm{pH}$-adjusted bleach decontamination of both concrete and wood surfaces was successful, when using either of the full application procedures (Tests 1 and 2) (Fig. 2). Despite the long-term historical use of bleach as a surface disinfectant (Rutala et al. 1998; Block 2001; Rutala and Weber 1997; Brazis et al. 1958), these results are somewhat surprising. Recent studies have reported incomplete inactivation of Bacillus spores on concrete and wood when decontaminated using $\mathrm{pH}$ adjusted bleach (Wood et al. 2011; Calfee et al. 2011). The higher surface reductions reported in this study may be attributed to surface sampling with wipes, as opposed to whole-coupon extraction methods used in the cited studies. Wipe sampling may underestimate the abundance of survivors as compared to extraction; however, it more accurately reflects techniques that would be used during an actual biological incident. Recoveries from positive controls samples were similar among the three studies (c. $1 \times 10^{7} \mathrm{CFU}$ ), suggesting that disparities in sampling efficiency are not likely the cause of the differences in decontamination efficacy. In addition, the pressure-treated wood coupons used in the current study may be easier to decontaminate than the untreated pine wood coupons used in the previous studies. Pressure-treated wood was selected for this study because it is common in animal facilities. In this study, the greater decontaminant spray velocities and the use of a rinse step may also explain why decontamination efficacies for bleach on wood were higher than those observed by Wood et al. (2011) and Calfee et al. (2011). These previous studies used hand-held spray devices to apply decontaminants to coupon surfaces.

Similarly, high surface reductions were observed for wood when Spor-Klenz ${ }^{\circledR}$ RTU was applied (Tests 3 and 4). In contrast, decontamination efficacy for concrete surfaces was much lower for Spor-Klenz ${ }^{\circledR}$ RTU. Previous studies have noted low efficacies for hydrogen peroxide/peracetic acid-based formulations on concrete surfaces (Calfee et al. 2011) and that concrete block had high reactivity (catalytic decomposition) with vaporous hydrogen peroxide (Procell et al. 2010). Therefore, these data are in agreement with previous studies, which suggest that hydrogen peroxide/peroxyacetic acid-based formulations may not be the best option for decontaminating concrete surfaces.

Surface decontamination efficacy of $\mathrm{pH}$-adjusted bleach was lower when the single application was used on wood (Test 5), where a 4 LR was achieved for this material (Fig. 2). These results, as well as those from other studies, suggest that the sporicidal activity (oxidation) of bleach is diminished by the high organic (reducing) content of wood (Calfee et al. 2011; Wood et al. 2011) or other materials (Weber et al. 1999; Hilgren et al. 2007). As such, bleach may not be the most effective decontaminant for wood surfaces, yet can be highly effective for surface removal/inactivation if sufficient quantities are applied so that material demand (reactivity) and the potential for relocation of contaminants into liquid runoff or aerosols are overcome. In addition, typical decontamination guidance requires heavily soiled surfaces to be cleaned before decontaminating with bleach, to reduce the organic demand by soil and/or grime.

Decontamination strategies following a biological contamination incident should be designed to minimize agent dispersal. Assessment of surface contamination reduction alone is not adequate for evaluating facilityscale decontamination approaches. Surface reduction can be accomplished by microbial inactivation on surfaces and/or by physical removal of viable or inactivated agent from surfaces. Removal of viable agent(s) from contaminated surfaces may facilitate the spread of contamination to previously uncontaminated areas. Such routes of contamination spread when using surface-applied liquid decontaminants include transport of viable agent(s) via liquid rinsate or generation of agent-containing aerosols. The potential for contamination spread by each of these routes was demonstrated during the current study.

Analysis of rinsate samples collected during decontamination testing indicated that the full procedures (Tests 1 through 4) resulted in little contamination spread by this route (Fig. 3). Of these, only in the test where $\mathrm{pH}$ adjusted bleach was applied with a gas-powered sprayer to wood (Test 2) was there detectable quantities of agent in the rinsate. When $\mathrm{pH}$-adjusted bleach was applied using the single application (Test 5), c. $1 \times 10^{4}$ and $1 \times 10^{5} \mathrm{CFU}$ were recovered in concrete and wood rinsates, respectively (Fig. 3). These data agree with the surface reduction data and suggest that incomplete inactivation on surfaces can lead to increased potential for spread of spores by liquid runoff. In addition, these data are more consistent with those of Calfee et al. (2011) and Wood et al. (2011) where incomplete inactivation was observed for these decontaminants, when used on wood and concrete.

It is important to reiterate that runoff samples were neutralized immediately and therefore approximate the maximum amount of contamination spread by this route. The neutralization of decontaminant in runoff during field applications is expected to range from very little to complete neutralization. For example, very little neutralization of runoff decontaminant may occur when decontaminating relatively clean indoor facilities, therefore biocidal activity may continue in the runoff. We speculate that in heavily soiled areas, neutralization of decontaminant in runoff may be complete, thereby inhibiting further biocidal activities once liquids leave the targeted surfaces. 
To further support the notion that incomplete surface inactivation can increase the likelihood of contamination dispersal, aerosol samples collected during Test 5 demonstrated the highest recovery of viable airborne agent (Fig. 4). Also consistent with rinsate results, aerosol samples collected during Test 2 were higher than that of Tests 1 and 4, but the lack of replication of aerosol samples limits the ability to accurately assess these differences. In addition, aerosol samples were not collected isokinetically within the airflow of the chamber, so these data should be used to qualitatively approximate trends in the formation of agent-containing aerosols between tests and materials, not as absolute quantities or air concentrations. Collection of decontaminant droplets by the air sampling cassette could have negatively biased results.

Surface sampling of smooth, nonporous materials such as stainless steel are known to yield higher and more repeatable recoveries than does sampling of porous and rough materials such as wood and concrete (Buttner et al. 2001; Probst et al. 2011). As such, stainless steel coupons were used as inoculation controls to demonstrate that consistent dosing was achieved for the cohort of test coupons inoculated for each day of testing. Recoveries were similar across all stainless steel coupons (within and between tests), indicating that the inoculation method was consistent. The minimum, maximum and mean recovery from stainless steel coupons were $1.83 \times 10^{7}, 2 \cdot 9 \times 10^{7}$ and $2.6 \times 10^{7} \mathrm{CFU}$, respectively (Fig. 1). Mean recoveries from concrete and wood positive control coupons were $c$. 9 and $17 \%$ of the stainless steel recovery, respectively. These recoveries are similar to those reported previously for environmental sampling of bacterial spores (Edmonds et al. 2009; Brown et al. 2007a; Buttner et al. 2004).

When conducting facility-scale decontamination, it may be important to reduce the amount of collateral damage to the facility caused by the procedure. For example, the use of oxidants and strong acids can result in corrosion of metal surfaces within a facility. Rinsing of surfaces with water following the completion of a decontamination procedure is commonly practiced to reduce such effects and was included in the current study. No adverse impacts to wood or concrete coupons were visually observed following treatment with $\mathrm{pH}$-adjusted bleach or Spor-Klenz ${ }^{\circledR}$ RTU, although observations were made only 2 days following treatment.

During this study, Test 4 was conducted prior to Test 2 , as it was expected that $\mathrm{pH}$-adjusted bleach may have deleterious effects on the gas-powered sprayer. The intention was to compete the test in which Spor-Klenz ${ }^{\circledR}$ RTU was applied by gas-powered sprayer first (Test 4), so that if the gas-powered sprayer was negatively affected by bleach (Test 2), the testing with Spor-Klenz ${ }^{\circledR}$ RTU would not be impacted. Unfortunately, the John Deere gas-pow- ered sprayer used for application of decontaminant during Test 4 was not compatible with Spor-Klenz ${ }^{\circledR}$ RTU, presumably owing to the low $\mathrm{pH}$ of Spor-Klenz ${ }^{\circledR}$ RTU ( $\mathrm{pH}$ c. 2). The consequences of this malfunction were that only three of six replicate wood coupons were included during Test 4, only one of two prescribed applications of Spor-Klenz ${ }^{\circledR}$ RTU was administered to this set of three replicate wood coupons, and a longer contact time (34 $\mathrm{min}$, as opposed to $30 \mathrm{~min}$ ) resulted because of extra time required to deploy a backup gas-powered sprayer (Troy-Bilt) for the rinse step. As surface reductions were high for wood during the affected test, and viable agent was not detected at high concentrations in the aerosol and rinsate, we concluded that the malfunction did not adversely affect the test results. To prevent such future malfunctions, a chemical resistant gas-powered sprayer was used for $\mathrm{pH}$-adjusted bleach application during Test 2. The backup gas-powered sprayer (Troy-Bilt ${ }^{\circledR}$ ) was used to rinse the wood coupons during Test 4 , and all coupons during Test 2.

In summary, decontamination of wood and concrete with $\mathrm{pH}$-adjusted bleach was highly effective for two applications, and a 30-min contact time, regardless of the device used to apply the decontaminant. Spor-Klenz ${ }^{\circledR}$ RTU was as effective as $\mathrm{pH}$-adjusted bleach on wood surfaces, but it was not highly effective for concrete decontamination. In all tests, viable spores were detected in the aerosol samples collected during decontamination procedures. Shortening the $\mathrm{pH}$-adjusted bleach procedure resulted in reduced surface decontamination efficacy on wood. Ineffective surface decontamination (e.g. Test 5) corresponded with an increased spread of contaminants by generation of aerosols and rinsates that contain viable biologicals. This study provides information on decontaminant selection, application procedures, material types, negative impacts on building materials and items, and potential for contamination spread, all important considerations when developing remediation plans following a biological contamination incident.

\section{Disclaimer}

The US Environmental Protection Agency through its Office of Research and Development directed the research described herein under EP-C-09-027 with ARCADIS Inc. This project was funded through an Interagency with the Science and Technology Directorate of the US Department of Homeland Security under Award Number HSHQDC-10-X-00148. This manuscript has been subject to an administrative review but does not necessarily reflect the views of the Agency. No official endorsement should be inferred. EPA does not endorse the purchase or sale of any commercial products or services. 


\section{References}

Block, S.S. (2001) Disinfection, Sterilization, and Preservation. Philadelphia, PA: Lippincott Williams and Wilkins.

Brazis, A.R., Leslie, J.E., Kabler, P.W. and Woodward, R.L. (1958) The inactivation of spores of Bacillus globigii and Bacillus anthracis by free available chlorine. Appl Environ Microbiol 6, 338-342.

Brown, G.S., Betty, R.G., Brockmann, J.E., Lucero, D.A., Souza, C.A., Walsh, K.S., Boucher, R.M., Tezak, M. et al. (2007a) Evaluation of a wipe surface sample method for collection of Bacillus spores from nonporous surfaces. Appl Environ Microbiol 73, 706-710.

Brown, G.S., Betty, R.G., Brockmann, J.E., Lucero, D.A., Souza, C.A., Walsh, K.S., Boucher, R.M., Tezak, M.S. et al. (2007b) Evaluation of vacuum filter sock surface sample collection method for Bacillus spores from porous and non-porous surfaces. J Environ Monit 9, 666-671.

Buttner, M.P., Cruz-Perez, P. and Stetzenbach, L.D. (2001) Enhanced detection of surface-associated bacteria in indoor environments by quantitative PCR. Appl Environ Microbiol 67, 2564-2570.

Buttner, M.P., Cruz, P., Stetzenbach, L.D., Klima-Comba, A.K., Stevens, V.L. and Cronin, T.D. (2004) Determination of the efficacy of two building decontamination strategies by surface sampling with culture and quantitative PCR analysis. Appl Environ Microbiol 70, 4740-4747.

Calfee, M.W., Choi, Y., Rogers, J., Kelly, T., Willenberg, Z. and Riggs, K. (2011) Lab-scale assessment to support remediation of outdoor surfaces contaminated with Bacillus anthracis spores. J Bioterr Biodef 2, 1-9.

Da Silva, S.M., Filliben, J.J. and Morrow, J.B. (2011) Parameters affecting spore recovery from wipes used in biological surface sampling. Appl Environ Microbiol, 77, 2374-2380.

Edmonds, J.M., Collett, P.J., Valdes, E.R., Skowronski, E.W., Pellar, G.J. and Emanuel, P.A. (2009) Surface sampling of spores in dry-deposition aerosols. Appl Environ Microbiol $75,39-44$.

Franco, C. and Bouri, N. (2010) Environmental decontamination following a large-scale bioterrorism attack: federal progress and remaining gaps. Biosecur Bioterror 8, 107-117.

Grand, I., Bellon-Fontaine, M.N., Herry, J.M., Hilaire, D., Moriconi, F.X. and Naïtali, M. (2010) The resistance of Bacillus atrophaeus spores to the bactericidal activity of peracetic acid is influenced by both the nature of the solid substrates and the mode of contamination. J Appl Microbiol 109, 1706-1714.

Hilgren, J., Swanson, K.M.J., Diez-Gonzalez, F. and Cords, B. (2007) Inactivation of Bacillus anthracis spores by liquid biocides in the presence of food residue. Appl Environ Microbiol 73, 6370-6377.

Krauter, P., Edwards, D., Yang, L. and Tucker, M. (2011) A systematic methodology for selecting decontamination strategies following a biocontamination event. Biosecur Bioterror 9, 262-270.
Lee, S.D., Ryan, S.P. and Snyder, E.G. (2011) Development of an aerosol surface inoculation method for Bacillus spores. Appl Environ Microbiol 77, 1638-1645.

McDonnell, G. and Russell, A.D. (1999) Antiseptics and disinfectants: activity, action, and resistance. Clin Microbiol Rev 12, 147-179.

Nakamura, L.K. (1989) Taxonomic relationship of blackpigmented Bacillus subtilis strains and a proposal for Bacillus atrophaeus sp. nov. Int J Syst Bacteriol 39, 295-300.

Probst, A., Facius, R., Wirth, R., Wolf, M. and Moissl-Eichinger, C. (2011) Recovery of Bacillus spore contaminants from rough surfaces: a challenge to space mission cleanliness control. Appl Environ Microbiol 77, 1628-1637.

Procell, L.R., Hess, Z.A., Gehring, D.G., Lynn, J.T., Bartram, P.W., Brickhouse, M.D., Lalain, T.A., Ryan, S.P. et al. (2010) Material Demand Studies: Materials Sorption of Vaporized Hydrogen Peroxide. Washington, DC: Environmental Protection Agency, EPA/600R-10-002.

Raber, E., Hibbard, W.J. and Greenwalt, R. (2011) The national framework and consequence management guidance following a biological attack. Biosecur Bioterror 9, 271-279.

Rutala, W. (2007) Disinfection, Sterilization and Antisepsis: Principles, Practices, Current Issues, and New Research. Washington, DC: Association for Professionals in Infection Control and Epidemiology.

Rutala, W.A. and Weber, D.J. (1997) Uses of inorganic hypochlorite (bleach) in health-care facilities. Clin Microbiol Rev 10, 597-610.

Rutala, W.R., Barbee, S.L., Aguiar, N.C., Sobsey, M.D. and Weber, D.J. (2000) Antimicrobial activity of home disinfectants and natural products against potential human pathogens. Infect Control Hosp Epidemiol 21, 33-38.

US Centers for Disease Control and Prevention (2010) [Online] Emergency Response Resources. Atlanta, GA. Available: http://www.cdc.gov/niosh/topics/emres/surfacesampling-bacillus-anthracis.html [Accessed September 14, 2011].

US Environmental Protection Agency (2007) Guidance on test methods for demonstrating the efficacy of antimicrobial products for inactivating Bacillus anthracis spores on environmental surfaces. In FIFRA Scientific Advisory Panel Meeting. Arlington, VA: US Environmental Protection Agency (SAP Minutes No. 2007-05).

Weber, D.J., Barbee, S.L., Sobsey, M.D. and Rutala, W.A. (1999) The effect of blood on the antiviral activity of sodium hypochlorite, a phenolic, and a quaternary ammonium compound. Infect Control Hosp Epidemiol 20, 821827.

Wood, J.P., Choi, Y.W., Rogers, J.V., Kelly, T.J., Riggs, K.B. and Willenberg, Z.J. (2011) Efficacy of liquid spray decontaminants for inactivation of Bacillus anthracis spores on building and outdoor materials. J Appl Microbiol 110, 1262-1273. 